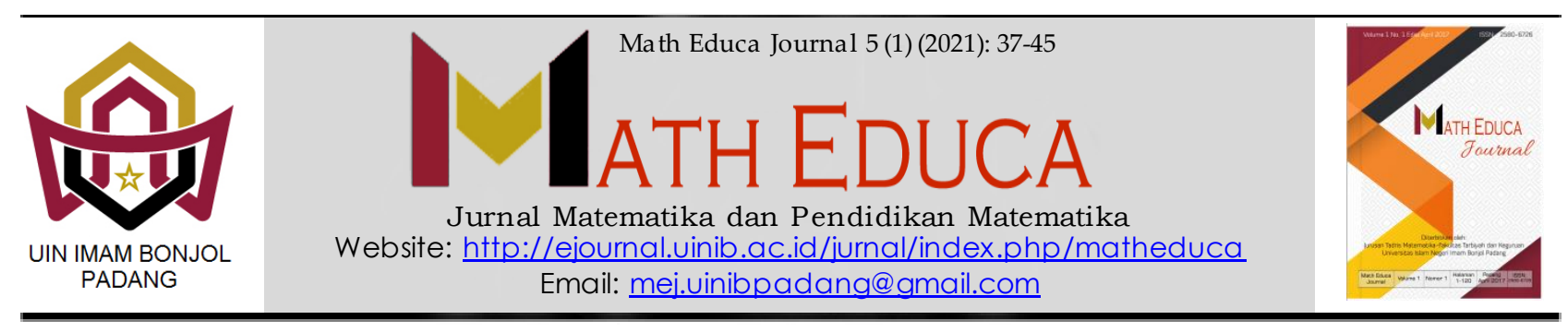

\title{
PENGARUH MODEL PEMBELAJARAN PROBING-PROMPTING YANG BERBASIS ETNOMATEMATIKA TERHADAP PRESTASI BELAJAR MATEMATIKA SISWA
}

\author{
'Osniman Paulina Maure*, ${ }^{2}$ Kondradus Silvester Jenahut \\ Matematika, Fakultas Matematika dan Ilmu Pengetahuan Alam, Universitas San Pedro, Indonesia \\ 2Pendidikan Guru Sekolah Dasar, Fakultas Keguruan dan Ilmu Pen didikan, Universitas San Pedro,Indonesia \\ E-mail: 'osnimanpaulinamaure@gmail.com , 22 silvesterienahut@gmail.com \\ Received: February 2021; Accepted: March 2021; Published: April 2021
}

\begin{abstract}
One of the reasons for the low student achievement in mathematics is that the mathematics learning process carried out by the teacher tends to be theoretical and less contextual. Mathematics learning needs to be linked to student culture so that there is no gap between mathematics in everyday life and at school. Thus, it is necessary to apply a mathematics learning model based on ethno-mathematics. This study aims to determine the effect of the ethnomatematic based probing-prompting learning model on students' mathematics learning achievement. This type of research is quantitative research with pre-experimental methods and one-group pretest-posttest design. The sample of this research is class VIII A SMPK St. Yoseph Naikoten Kupang, totaling 24 people. The pretest and posttest values as research data were analyzed using the SPSS version 22 program. Based on the results of data analysis, $t_{\text {hitung }}(39,594)>t_{\text {tabel }}(2,069)$ with an error rate of 0.05 , which means accept Ha or the ethnomatematic based probing-prompting learning model has an influence which is significant towards the mathematics learning achievement of students class VIII SMPK St. Yoseph Naikoten Kupang.
\end{abstract}

Keywords: Learning model, ethnomatematics, probing-prompting, learning achievement

\begin{abstract}
Abstrak
Salah satu penyebab rendahnya prestasi belajar matematika siswa yaitu proses pembelajaran matematika yang dilaksanakan guru lebih bersifat teoritis dan kurang kontekstual. Pembelajaran matematika perlu dikaitkan dengan budaya siswa agar tidak ada gap antara matematik di kehidupan sehari-hari dan di sekolah. Dengan demikian, perlu diterapkan suatu model pembelajaran matematika yang berbasis etnomatematika. Penelitian ini bertujuan untuk mengetahui pengaruh model pembelajaran probingprompting yang berbasis etnomatematika terhadap prestasi belajar matematika siswa. Jenis penelitian ini yaitu penelitian kuantitatif dengan metode pre-eksperimen dan one-group pretest-posttest design. Sampel penelitian ini yaitu kelas VIII A SMPK St. Yoseph Naikoten Kupang berjumlah 24 orang. Nilai pretest dan posttest sebagai data penelitian ini dianalisis menggunakan program SPSS versi 22. Berdasarkan hasil analisis data, $t_{\text {hitung }}(39,594)>t_{\text {tabel }}(2,069)$ dengan tingkat kesalahan 0,05 yang berarti terima $\mathrm{Ha}$ atau model pembelajaran probing-prompting yang berbasis etnomatematika memiliki pengaruh yang signifikan terhadap prestasi belajar matematika siswa kelas VIII SMPK St. Yoseph Naikoten Kupang.
\end{abstract}

Kata kunci: Model pembelajaran, etnomatematika, probing-prompting, prestasi belajar

\footnotetext{
${ }^{*}$ Corresponding author.

Peer review under responsibility UIN Imam Bonjol Padang.

(C) 2021 UIN Imam Bonjol Padang. All rights reserved.

p-ISSN: $2580-6726$

e-ISSN: 2598-2133
} 


\section{PENDAHULUAN}

Salah satu cara menginvestasi sumber daya manusia jangka panjang yaitu melaui pendidikan, dimana salah satu komponen terpentingnya adalah peran seorang guru (Riadi, 2017). Hal ini dikarenakan guru merupakan perencana, pelaksana, maupun evaluator dalam pembelajaran (Zulfiati, 2014). Keberhasilan suatu proses pembelajaran yang dilaksanakan oleh seorang guru dapat diukur melalui prestasi belajar yang dicapai oleh para siswa (Suyati, 2015). Namun berdasarkan realitanya, prestasi belajar matematika para siswa belum memenuhi standar. Berdasarkan rerata nilai UN matematika SMP/MTs di tingkat nasional sejak tahun 2016 sampai tahun 2019 berada di bawah standar yang diperlihatkan pada Tabel 1.

\section{Tabel 1. Rata-rata Nilai UN}

\begin{tabular}{ccccc}
\hline \multirow{2}{*}{ Statistik } & \multicolumn{4}{c}{ Tahun Pelajaran } \\
\cline { 2 - 5 } & 2016 & 2017 & 2018 & 2019 \\
\hline Kategori & Kurang & Kurang & Kurang & Kurang \\
\hline Rata-rata & 50,24 & 50,31 & 43,34 & 45,52 \\
\hline
\end{tabular}

(Pusat Penilaian Pendidikan Kementerian

Pendidikan dan Kebudayaan, 2021)

Berdasarkan hasil wawancara dengan seorang guru matematika di SMPK St. Yoseph Naikoten Kupang, rata-rata hasil UN SMPK St. Yoseph Naikoten Kupang tahun 2019 mengalami penurunan dari tahun 2018.

Hal ini dikarenakan pembelajaran matematika yang dilaksanakan guru lebih bersifat teoritis dan kurang kontekstual. Pembelajaran matematika perlu dikaitkan dengan budaya siswa agar tidak ada gap antara matematika dalam kehidupan siswa sehari-hari dan pengajaran matematika di sekolah. Pengetahuan guru tentang keberagaman budaya yang dimiliki siswa akan sangat membantu untuk keberhasilan pelaksanaan pendidikan (Dantes, 2014). Hal ini dikarenakan pada suatu budaya memuat berbagai konsep matematika yang secara tidak sadar diterapkan masyarakat dalam kehidupan sehari-hari, misalkan pada bidang perternakan, perdagangan, pertanian, dan sebagainya (Dahlan \& Permatasari, 2018). Oleh sebab itu, perlu digunakan suatu model pembelajaran matematika yang mampu mengintegrasikan kehidupan budaya para siswa ke dalam pembelajaran matematika. Apabila matematika diintegrasikan dengan bidang lain contohnya unsur budaya, matematika tersebut akan lebih kontekstual (Sugilar et al., 2019).

Model pembelajaran probingprompting yang berbasis etnomatematika merupakan suatu model pembelajaran yang mampu menyelesaikan persoalan yang dikemukan di atas. Probing-prompting merupakan dua kata yang memiliki arti menyelidiki (probing) dan menuntun (prompting) (Megasari et al., 2018). Probingprompting merupakan suatu model pembelajaran yang dilakukan dengan teknik seorang guru memaparkan berbagai pertanyaan yang bersifat menyelidiki dan membimbing proses berpikir siswa agar mampu menghubungkan pengalaman maupun pengetahuan siswa dengan pengetahuan yang baru (Huda, 2013). Probing-prompting ini bersifat student centered dimana para siswa diberikan kebebasan agar terlibat aktif untuk mengkonstruksi pengetahuannya sendiri, sedangkan guru hanya menjadi mediator dan fasilitator saat proses belajar mengajar berlangsung (Jayanti, 2018).

Tahapan dalam model pembelajaran probing-prompting ini yaitu sebagai berikut (Lestari \& Yudhanegara, 2015): (1) Siswa diberikan suatu gambar, rumus, atau situasi lain yang memuat suatu masalah yang sesuai dengan tujuan pembelajaran, (2) Siswa diberikan kebebasan untuk merangkai jawabannya sendiri, (3) Siswa dipersilahkan menjawab pertanyaan, (4) Apabila jawaban siswa tersebut benar, guru akan meminta respon siswa lain terhadap jawaban tersebut 
agar memastikan semua siswa perperan aktif selama proses pembelajaran. Namun, apabila ada siswa yang sulit memberikan jawaban dengan benar, guru akan mengajukan pertanyaan lain dimana jawabannya adalah petunjuk alur pemecahan masalah. Siswa lalu diberikan pertanyaan lanjutan yang bersifat membimbing siswa untuk berpikir ke tingkat lebih tinggi yang secara tidak langsung menuntun siswa pada tujuan pembelajaran, dan (5) Siswa diberikan pertanyaan akhir yang berbeda agar lebih menekankan bahwa tujuan pembelajaran telah tercapai dengan baik.

Etnomatematika adalah suatu disiplin ilmu yang mempelajari keterkaitan antara suatu budaya masyarakat dengan matematika (Maure \& Ningsi, 2018). Budaya diartikan sebagai kemampuan dari akal atau budi yang meliputi cipta, kehendak, dan rasa (Beni, 2020). Kebudayaan meliputi suatu kebiasaan, nilai-nilai, tradisi, bahasa, norma, dan pola berpikir suatu komunitas masyarakat yang merupakan warisan dari suatu generasi ke generasi lainnya sebagai identitas komunitas tersebut (Putra, 2013). Seorang penggagas etnomatematika,

D'Ambrosio mengungkapkan bahwa etnomatematika merupakan ilmu yang mengkaji aspek matematika yang dilakukan oleh suatu masyarakat misalnya kelompok pribumi, pekerja profesional, kelompok pekerja, individu kelompok usia tertentu, dan sebagainya (Ambrosio, 1985). Pengetahuan tentang etnomatematika ini berguna untuk meningkatkan pengetahuan, minat, dan pemahaman akan matematika yang diajarkan seorang guru (Jenahut \& Maure, 2020). Dengan demikian, model pembelajaran probing-prompting yang berbasis etnomatematika adalah suatu model pembelajaran yang memuat berbagai pertanyaan berbasis etnomatematika guna menyelidiki dan membimbing proses berpikir siswa.
Beberapa penelitian mengungkapkan bahwa hasil belajar matematika siswa kelas $X$ SMA Negeri 1 Sukasada yang diajarkan dengan model pembelajaran probing-prompting berbantuan index card match lebih berpengaruh positif dibandingkan dengan model pembelajaran konvensional (Setiawati et al., 2019), prestasi belajar matematika siswa yang diajarkan menggunakan model pembelajaran probing-prompting lebih unggul dari pada model pembelajaran konvesional (Fauziah \& Mansur, 2017), model pembelajaran probing-prompting berpengaruh secara positif dilihat dari hasil belajar dibandingkan dengan model pembelajaran SQ4R (Jatmiko, 2017), model pembelajaran probing-prompting dan etnomatematika dapat dikolaborasikan dalam pembelajaran matematika guna melatih komunikasi matematis siswa (Kurniawan et al., 2019), dan model pembelajaran probingprompting yang berbasis etnomatematika memiliki pengaruh yang signifikan terhadap kompetensi pengetahuan matematika siswa kelas V SD Gugus Letda Made Putra Kecamatan Denpasar Utara (Radiana et al., 2020).

Dengan demikian, peneliti ingin mengetahui pengaruh model pembelajaran probing-prompting yang berbasis etnomatematika terhadap prestasi belajar matematika siswa kelas VIII SMPK St. Yoseph Naikoten Kupang. Peneliti menggunakan etnomatematika yang terdapat di Nusa Tenggara Timur (NTT) sebagai referensi dalam mengajarkan materi kubus dan balok.

\section{METODE PENELITIAN}

\section{Jenis Penelitian}

Penelitian ini merupakan penelitian kuantitatif dengan menggunakan metode preeksperimen dan The One-Group PretestPosttest Design seperti yang diskemakan pada Tabel 2. 
Tabel 2. The One-Group Pretest-Posttest

\begin{tabular}{ccc}
\hline Pretest & Treatment & Posttest \\
\hline O1 & $\mathrm{X}$ & $\mathrm{O} 2$ \\
\hline (Lestari \& Yudhanegara, 2015)
\end{tabular}

Keterangan:

$\mathrm{O}_{1}$ : Pretest sebagai alat ukur kemampuan awal siswa

$X$ : Treatment melalui penerapan model pembelajaran probing-prompting yang berbasis etnomatematika

$\mathrm{O}_{2}$ : Posttest sebagai alat ukur kemampuan akhir siswa

\section{Waktu dan Tempat Penelitian}

Penelitian ini dilakukan selama II bulan yaitu bulan September-Oktober tahun ajaran 2019/2020 yang dilaksanakan di SMPK St. Yoseph Naikoten Kupang.

\section{Populasi dan Sampel}

Populasi penelitian ini yaitu semua siswa kelas VIII SMPK St. Yoseph Naikoten Kupang berjumlah 169 orang dari 6 kelas. Berdasarkan teknik cluster random sampling diperoleh kelas VIII A SMPK St. Yoseph Naikoten Kupang berjumlah 24 siswa sebagai sampel penelitian ini.

\section{Prosedur}

Prosedur pengambilan data pada penelitian ini adalah sebagai berikut:

a. Peneliti membagikan pretest kepada siswa yang menjadi sampel penelitian.

b. Peneliti melaksanakan pertemuan sesuai Rencana Pelaksanaan Pembelajaran (RPP).

c. Peneliti membagikan posttest kepada sampel penelitian.

d. Peneliti menganalisis data hasil pretest dan posttest.

\section{Data, Intrumen, dan Teknik Pengumpulan Data}

Data primer pada penilitian ini diambil oleh peneliti secara langsung dari kelas sampel berupa hasil pretest dan posttest. Instrumen penelitian ini yaitu tes prestasi belajar matematika yang berbentuk tes uraian, sedangkan teknik pengumpulan data berupa tes prestasi belajar.

\section{Teknik Analisis Data}

Data pretest dan posttest dianalisis dengan menggunakan program SPSS versi 22. Tahapan analisis data dalam penelitian ini meliputi:

a. Uji Normalitas

Dalam pengujian normalitas data pretest dan posttest digunakan uji Kolmogorov-smirnov. Hipotesis pada pengujian normalitas ini yaitu:

$\mathrm{Ho}=$ Data berdistribusi normal

$\mathrm{Ha}=$ Data tidak berdistribusi normal

Apabila hasil perhitungan menunjukan $D_{\text {hitung }} \leq D_{\text {tabel }}$ maka Ho diterima atau data berdistribusi normal. Akan tetapi, apabila $D_{\text {hitung }}>D_{\text {tabel }}$ maka tolak Ho atau data tidak berdistribusi normal.

b. Uji Hipotesis

Jika data berdistribusi normal, peneliti melakukan pengujian statistik parametrik menggunakan uji-t dengan rumus perbandingan dua rata-rata untuk sampel related yaitu:

1. Merumuskan hipotesis

Ho : tidak ada pengaruh yang signifikan pada penggunaan model pembelajaran matematika probingprompting yang berbasis etnomatematika terhadap prestasi belajar matematika siswa pokok bahasan kubus dan balok kelas VIII di SMPK St. Yoseph Naikoten Kupang.

$\mathrm{Ha}$ : ada pengaruh yang signifikan pada penggunaan model pembelajaran matematika Probing-prompting yang berbasis etnomatematika terhadap prestasi belajar matematika siswa pokok bahasan kubus dan balok kelas VIII di SMPK St. Yoseph Naikoten Kupang. 
2. Menentukan Kriteria Pengujian Hipotesis

Jika $-t_{\frac{\partial}{2}} \leq t_{\text {hitung }} \leq t_{\frac{\partial}{2}}$, maka terima Ho dan tolak Ha dan jika $t_{\text {hitung }}>t_{\frac{\partial}{2}}$ atau $t_{\text {hitung }}<-t_{\frac{\partial}{2}}$, maka tolak Ho dan terima Ha.

\section{HASIL PENELITIAN DAN PEMBAHASAN}

\section{Hasil Penelitian}

Peneliti

menerapkan

model

pembelajaran probing-prompting yang berbasis etnomatematika saat mengajarkan materi kubus dan balok selama melaksanakan penelitian. Berikut ini adalah beberapa contoh soal kubus dan balok berbasis etnomatematika yang digunakan peneliti.

1. Seorang pengrajin di kota Kupang akan membuat sebuah kotak persembahan untuk diletakkan di suatu gereja berbentuk kubus dengan motif kain adat Manggarai (songke). Kotak persembahan ini akan diletakkan di suatu gereja di Kota Kupang. Jika panjang rusuk kubus $50 \mathrm{~cm}$, tentukan luas kain songke yang diperlukan untuk membuat kotak pesembahan tersebut.

2. Kerajinan anyaman bambu seperti pada Gambar 1 merupakan sebuah kubus yang memiliki panjang rusuk $1 \mathrm{~m}$. Anyaman bambu ini biasa digunakan oleh masyarakat NTT sebagai tempat penyimpanan makanan lokal seperti jagung, umbi, keladi, talas, singkong, ubi jalar, dan berbagai umbi hutan.

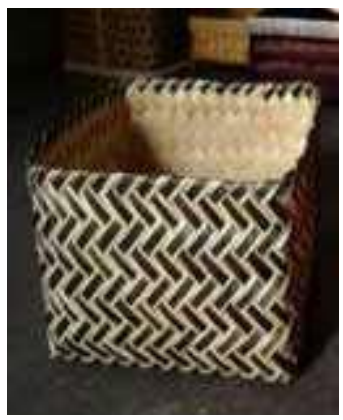

Gambar 1. Anyaman bambu

Tentukan volume diagonal sisinya dan diagonal bidangnya.
3. Sirih pinang merupakan cemilan khas masyarakat NTT terutama masyarakat di daerah Timor. Tempat penyimpanan sirih pinang ini disebut Okomama yang terbuat dari daun lontar berbentuk balok seperti pada Gambar 2.

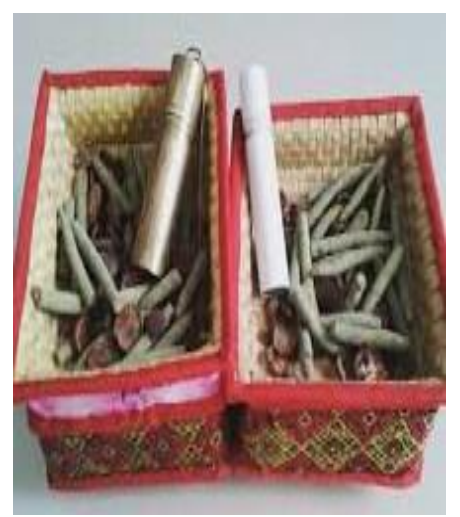

Gambar 2. Okomama

Jika diketahui panjangnya $1,5 \mathrm{~m}$, lebar $1 \mathrm{~m}$ dan tinggi 0,05 m, maka tentukanlah luas permukaan Okomama berbentuk balok (cm) dan volume Okomama berbentuk balok $(\mathrm{cm})$.

4. Lego-lego merupakan tarian khas masyarakat di Kabupaten Alor. Para penari biasanya menggunakan tas yang berisi sirih pinang yang terbuat dari daun koli berbentuk balok tanpa tutup seperti Gambar 3.

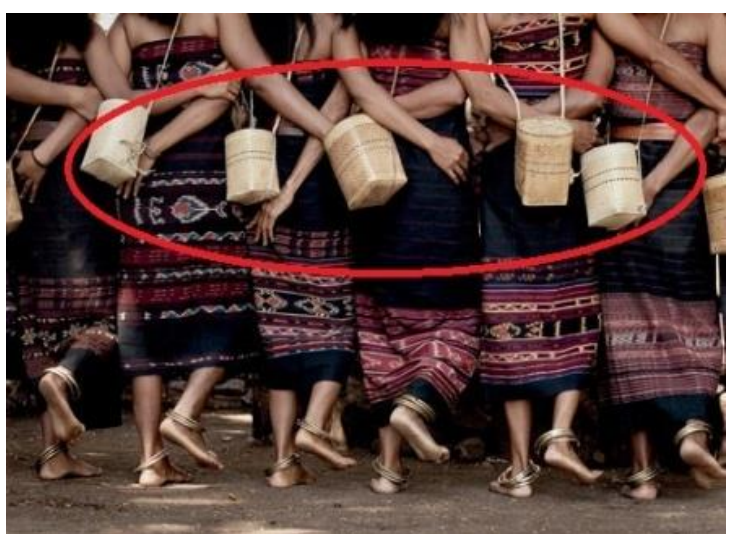

Gambar 3. Penari lego-lego menggunakan tas berbentuk balok

Jika luas permukaan benda tersebut 198 $\mathrm{cm}^{2}$, lebarnya $16 \mathrm{~cm}$ dan panjangnya setengah dari lebarnya ditambah $22 \mathrm{~cm}$, maka tentukanlah tinggi benda tersebut. 
5. Al Quran tertua di Alor merupakan Al Quran tertua di Asia Tenggara yang diperkirakan berusia hampir 1000 tahun dan masih utuh hingga sekarang. Kotak penyimpan Al Quran ini terbuat dari kayu berbentuk balok seperti pada Gambar 4 .

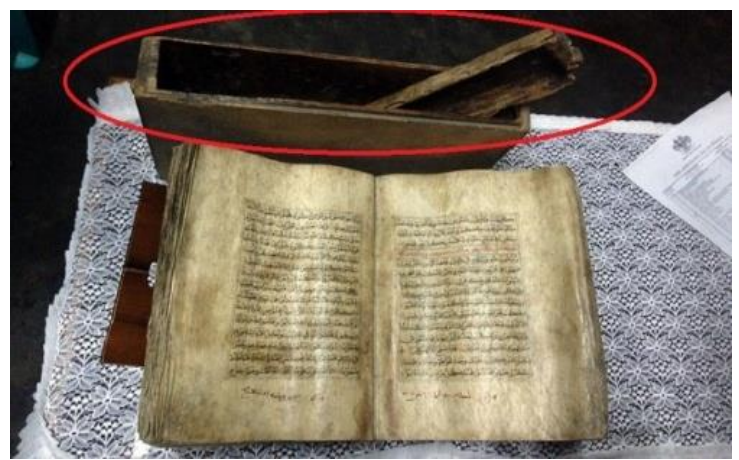

Gambar 4. Al Quran tertua seAsia Tenggara

Jika panjang, lebar dan tinggi kotak tersebut masing-masing $30 \mathrm{~cm}, 15 \mathrm{~cm}$ dan $35 \mathrm{~cm}$ maka hitunglah luas permukaan kotak tersebut.

Berdasarkan hasil penelitian, peneliti memperoleh data nilai pretest dan posttest dari kelas sampel seperti pada Gambar 5 .

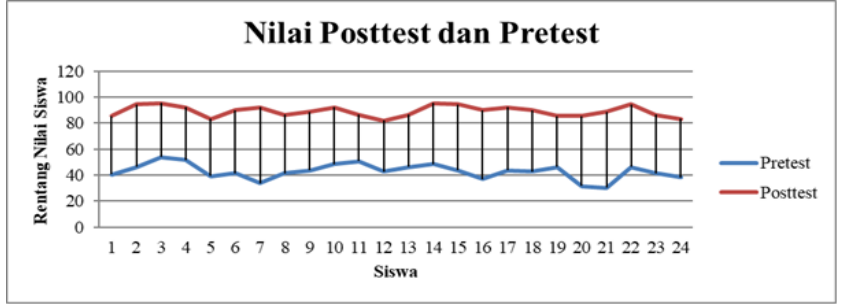

Gambar 5. Nilai posttest dan pretest siswa

Selanjutnya, data ini dianalisis menggunakan SPSS versi 22 untuk meninjau pengaruh model pembelajaran probingprompting yang berbasis etnomatematika terhadap prestasi belajar matematika siswa pokok bahasan kubus dan balok di SMPK St. Yoseph Naikoten Kupang. Hasil analisis data ini adalah sebagai berikut:

\section{a. Uji Normalitas}

\section{Data pretest}

Hasil analisis uji normalitas dengan $\alpha=0,05$ memperlihatkan bahwa nilai
Asymp.Sig. $(2-$ tailed $)=0,200 \quad$ dan $D_{\text {hitung }}=0,121$. Hal ini menunjukkan bahwa Asymp.Sig. $(2-$ tailed $)=0,200>0,05$ dan $D_{\text {hitung }}=0,121<0,269=D_{\text {tabel }}$. Dengan demikian, disimpulkan terima $\mathrm{H}_{0}$ atau data pretest berdistribusi normal.

\section{Data posttest}

Hasil analisis uji normalitas dengan $\alpha=0,05 \quad$ memperlihatkan bahwa Asymp. Sig. (2-tailed) $=0,200$ dan $D_{\text {hitung }}=$ 0,120. Hal ini menunjukkan bahwa Asymp. Sig. (2-tailed) $=0,200>0,05$, sedangkan $D_{\text {hitung }}=0,120<0,269=D_{\text {tabel }}$. Dengan demikian, disimpulkan terima $\mathrm{H}_{\mathrm{o}}$ atau data posttest berdistribusi normal.

\section{b. Uji Hipotesis}

Berdasarkan hasil analisis data pretest dan posttest, peneliti memperoleh Sig. (2tailed $)=0,000$, nilai $t_{\text {hitung }}=39,594$ dan $t_{\text {tabel }}=2,069$. Hal ini menunjukkan bahwa Sig. $(2-$ tailed $)=0,000<0,05=\alpha \quad$ dan $t_{\text {hitung }}=39,594>2,069=t_{\text {tabel }}$.

Berdasarkan kriteria penerimaan dan penolakan $\mathrm{H}_{\mathrm{o}}$ dengan taraf signifikansi $5 \%$ dan $t_{\text {hitung }}>t_{\text {tabel }}$, maka disimpulkan tolak $\mathrm{H}_{\mathrm{o}}$ dan terima $\mathrm{H}_{\mathrm{a}}$. Hal ini menerangkan bahwa ada pengaruh yang signifikan pada penerapan model pembelajaran probing-prompting yang berbasis etnomatematika terhadap prestasi belajar matematika siswa pokok bahasan kubus dan balok kelas VIII di SMPK St.Yoseph Naikoten Kupang.

\section{Pembahasan}

Berdasarkan data nilai pretest dan posttest dari kelas sampel pada Gambar 5, terlihat bahwa semua siswa mengalami peningkatan prestasi belajar. Hal ini senada dengan penelitian Susanti dkk yang mengungkapkan bahwa penggunaan model pembelajaran probing-prompting mampu meningkatkan prestasi belajar siswa secara signifikan (Susanti et al., 2017) dan hasil penelitian Hendrawan dkk menyatakan bahwa model pembelajaran probing-prompting berpengaruh secara positif terhadap prestasi 
belajar matematika siswa (Hendrawan et al., 2019). Hal ini didukung oleh data hasil pengujian hipotesis yang menerangkan bahwa penerapan model pembelajaran probingprompting yang berbasis etnomatematika berpengaruh secara signifikan terhadap prestasi belajar matematika siswa pokok bahasan kubus dan balok kelas VIII di SMPK St. Yoseph Naikoten Kupang.

Peneliti mengangkat masalah yang berkaitan dengan budaya siswa, diantaranya tempat penyimpanan sirih pinang (Okomama) berbentuk kubus, anyaman bambu berbentuk kubus, kain adat Manggarai (songke), kotak penyimpan Al Quran tertua seAsia Tenggara yang berada di Alor berbentuk balok, rumah adat masyarakat Nusa Tenggara Timur (NTT), dan lain-lain. Masalah ini disajikan pada tahap awal proses pembelajaran dan disajikan melalui Microsoft Power Point atau Lembar Kerja Siswa. Hal ini senada dengan teori Vygotsky yang mengungkapkan bahwa kegiatan sosial kultural tidak dapat dipisahkan dari perkembangan anak dan keberhasilan pembelajaran lebih baik apabila dikaitkan dengan realita kehidupan seorang anak (Utami, 2016).

Selama proses pembelajaran berlangsung, siswa menyatakan bahwa matematika yang dijumpai siswa sebelumnya tidak memiliki keterkaitan dengan budaya NTT, namun setelah mengikuti pembelajaran ini siswa mengetahui bahwa matematika memiliki keterkaitan dengan budaya NTT. Dalam hal ini, siswa tidak hanya diajarkan untuk mengetahui matematika saja tetapi juga untuk mengetahui budaya NTT yang berkaitan dengan matematika. Hal ini dikarenakan belajar merupakan proses memperoleh suatu pengetahuan baru berdasarkan pengetahuan yang didapatkan sebelumnya, namun memunculkan perhatian kembali bagi siswa tersebut (Aunurrahman, 2013).

Selama pelaksanaan proses pembelajaran ini, siswa terlihat terlibat aktif dalam menjawab setiap pertanyaan yang dipaparkan peneliti. Beberapa siswa juga memberikan contoh tentang materi yang sedang dipelajari yang berkaitan dengan budaya siswa. Hal ini secara langsung mampu melatih kemampuan komunikasi matematika siswa sebagaimana dengan hasil penelitian Kurniawan dkk yang mengungkapkan bahwa kolaborasi antara etnomatematika dan model pembelajaran probing-prompting mampu melatih komunikasi matematika siswa (Kurniawan et al., 2019).

\section{SIMPULAN DAN SARAN}

\section{Simpulan}

Model pembelajaran probingprompting yang berbasis etnomatematika memiliki pengaruh yang signifikan terhadap prestasi belajar matematika siswa pokok bahasan kubus dan balok di kelas VIII SMPK St. Yoseph Naikoten Kupang. Penerapan model pembelajaran ini dapat membangkitkan motivasi belajar siswa dan melatih kemampuan komunikasi matematika siswa. Penggunaan etnomatematika selama penelitian ini memberikan kemudahan kepada siswa untuk lebih memahami materi kubus dan balok yang diberikan peneliti. Hal ini disebabkan materi tersebut disajikan dalam konteks budaya para siswa yaitu budaya NTT.

\section{Saran}

Peneliti selanjutnya dapat menerapkan model pembelajaran probing-prompting yang berbasis etnomatematika agar meningkatkan prestasi belajar matematika siswa maupun melatih kemampuan komunikasi siswa. Etnomatematika yang diangkat tentunya yang berkaitan dengan budaya siswa.

\section{REFERENSI}

Ambrosio, U. D. (1985). Ethnomathematics and its Place in the History and Pedagogy of Mathematics. For the Learning of Mathematics, 5(1), 44-48.

Aunurrahman. (2013). Belajar dan Pembelajaran. Alfabeta.

Beni, S. (2020). Siklus Tahunan Budaya Dayak Djongkakng Di Dusun Jambu Desa 
Semirau Kecamatan Jangkang Kabupaten Sanggau Provinsi Kalimantan Barat. Jurnal Penelitian Sejarah Dan Budaya, 6(2), 221247. https://doi.org/10.36424/jpsb.v6i2.192

Dahlan, J. A., \& Permatasari, R. (2018). Pengembangan Bahan Ajar Berbasis Etnomatematika dalam Pembelajaran Matematika Sekolah Menengah Pertama. JNPM (Jurnal Nasional Pendidikan Matematika), 2(1), 133-150.

Dantes, N. (2014). Landasan Pendidikan. In Landasan Pendidikan. Graha IImu.

Fauziah, S. N. Q., \& Mansur. (2017). Pengaruh Penggunaan Model Pembelajaran Probing Prompting Terhadap Hasil Belajar Siswa pada Mata Pelajaran Matematika. Primary, 09(02), 243-268.

Hendrawan, T., Kasdi, A., \& Sukartiningsih, W. (2019). Pengaruh Model Pembelajaran Probing-Prompting Terhadap Hasil Belajar Siswa Di Kelas V Sekolah Dasar. Jurnal Review Pendidikan Dasar: Jurnal Kajian Pendidikan Dan Hasil Penelitian, 5(3), 1084-1091.

http://journal.unesa.ac.id/index.php/PD

Huda, M. (2013). Model-model Pengajaran dan Pembelajaran. Pustaka Belajar.

Jatmiko, D. D. H. (2017). Perbedaan Pengaruh Model Pembelajaran Probing Prompting Dan Sq4R Siswa Madrasah Aliyah. Jurnal Gammath, 2(1), 162-175.

Jayanti, R. (2018). Pembelajaran Menggunakan Teknik Probing Prompting Berbantuan Edmodo Blended Learning Pada Materi Persamaan Diferensial Matematis Mahasiswa Di Universitas Pgri Palembang. Journal of Chemical Information and Modeling, 53(9), 1689-1699.

Jenahut, K. S., \& Maure, O. P. (2020). Banga Masyarakat Manggarai Timur. 9(1), 138151.

Kurniawan, A. P., Anam, A. C., Abdussakir, \& Rofiki, I. (2019). Integrasi Etnomatematika Dengan Model Pembelajaran ProbingPrompting Untuk Melatih Komunikasi Matematis Siswa. MaPan, 7(1), 1-15. https://doi.org/10.24252/mapan.2019v7n1a

1

Lestari, K. E., \& Yudhanegara, M. R. (2015). Penelitian Pendidikan Matematika. PT. Refika Aditama.

Maure, P. O., \& Ningsi, G. P. (2018). Eksplorasi Etnomatematika pada Tarian Caci Masyarakat Mangarai Nusa Tenggara Timur. Posiding Seminar Nasional Etnomatnesia, 340-347. http://jurnal.ustjogja.ac.id/index.php/etno matnesia/index

Megasari, M., Sundaryono, A., \& Firdaus, M. L. (2018). Pembelajaran probing prompting untuk meningkatkan berpikir kritis siswa anggota kelompok ilmiah remaja. PENDIPA Journal of Science Education, 2(2), 163-169. https://doi.org/10.33369/pendipa.2.2.163169

Pusat Penilaian Pendidikan Kementerian Pendidikan dan Kebudayaan. (2021). Laporan Ujian Nasional. https://hasilun.puspendik.kemdikbud.go.i d/\#2016-2017-20182019!smp!capaian_wilayah!99\&99\&999!T \&T\&T\&T\&1\&!1!\&

Putra, A. A. N. A. (2013). Konseling Lintas Budaya. Graha Ilmu.

Radiana, P. R., Wiarta, I. W., \& Wiyasa, I. K. N. (2020). Pengaruh Model Pembelajaran Probing Prompting Berbasis Etnomatematika. 2(1), 32-40.

Riadi, A. (2017). Kompetensi Guru dalam Pelaksanaan Evaluasi Pembelajaran. Ittihad Jurnal Kopertais Wilayah XI Kalimantan, 15(28), 52-67.

Setiawati, D. A. O., Sudiarta, I. G. P., \& Ardana, I. M. (2019). Pengaruh Model Pembelajaran Probing Prompting Berbantuan Index Card Match Terhadap Prestasi Belajar Matematika Siswa Kelas X SMA Negeri 1 Sukasada. Jurnal Pendidikan Dan Pembelajaran Matematika Indonesia, 8(1), 71-81. https://doi.org/10.23887/jppm.v8i1.2845 
Sugilar, H., Rachmawati, T. K., \& Nuraida, I. (2019). Integrasi interkoneksi matematika agama dan budaya. Jurnal Analisa, 5(2), 189-198.

https://doi.org/10.15575/ja.v5i2.6717

Susanti, E., Sukasno, \& Refianti, R. (2017). Penerapan Model Probing-Prompting Pada Pembelajaran Matematika Siswa Kelas Viii Smp Negeri 1 Muara Kelingi Tahun Pelajaran 2016/2017. 1-11.

Suyati. (2015). Peningkatan Prestasi Belajar Siswa dalam Mata Pelajaran Matematika Operasi Hitung Perkalian dengan Metode
Bermain Kartu. Jurnal Paradigma, Volume 2(1).

Utami, I. G. A. L. P. (2016). Teori Konstruktivisme dan Teori Sosiokultural: Aplikasi dalam Pengajaran Bahasa Inggris. Prasi, 11(01), 4-11. https://ejournal.undiksha.ac.id/index.php/ PRASI/article/download/10964/7022

Zulfiati, H. M. (2014). Peran dan fungsi guru Sekolah Dasar dalam memajukan dunia pendidikan. Trihayu: Jurnal Pendidikan KeSD-An, 1(1), 1-4. 